\title{
ANALISIS PROGRAM LATIHAN SEPAK BOLA GRASS ROOT DAN IMPLEMENTASINYA PADA SEKOLAH SEPAK BOLA (SSB) KABUPATEN KEPAHIANG
}

\author{
Juli Handoko \\ Program Studi Pendidikan Jasmani FKIP Universitas Bengkulu \\ Email : kerenhandoko@gmail.com \\ Tono Sugihartono \\ Universitas Bengkulu \\ Ari Sutisyana \\ Universitas Bengkulu
}

\begin{abstract}
Abstrak
Penelitian ini bertujuan untuk mengetahui kesesuaian program latihan Sekolah Sepak Bola Kabupaten Kepahiang dengan program latihan Sepak Bola Grass Root . Metode yang digunakan adalah metode penelitian deskriptif. Subjek penelitian adalah 3 Sekolah Sepak Bola (SSB) di Kabupaten Kepahiang. Instrumen penelitian ini adalah Observasi, Wawancara, dan Dokumentasi. Berdasarkan perolehan data Sekolah Sepak Bola Kabupaten Kepahiang harus memperhatikan program latihan yang cocok untuk anak usia 6-12 tahun. Perbandingan rata-rata persentase susunan latihan SSB Kepahiang dengan susunan latihan Grass Root yaitu : Pemanasan $11,57 \%$ berbanding $13,33 \%$, fisik $23,15 \%$ berbanding $13,33 \%$, teknik $28,70 \%$ berbanding $33,33 \%$, permainan $28,70 \%$ berbanding $33,33 \%$, pendinginan $9,73 \%$ berbanding $6,7 \%$. Jadi hasil data yang diperoleh dari tiga Sekolah Sepak Bola di Kabupaten Kepahiang program latihan yang ada belum sesusai dengan program latihan Grass Root yang direkomendasikan oleh Indra Sjafri dan ada program latihan yang belum diterapkan pada saat latihan.
\end{abstract}

Kata Kunci : Program Latihan, Grass Root, Sepak Bola, Sekolah Sepak Bola

\begin{abstract}
This study aims to determine the suitability of the Kepahiang District Soccer School training program with the Grass Root Soccer training program. The method used is descriptive research method. The research subjects were 3 Football Schools (SSB) in Kepahiang District. The instruments of this study are Observation, Interview, and Documentation. Based on the data obtained from the Kepahiang District Football School, the training program is suitable for children aged 6-12 years. Comparison of the average percentage of Kepahiang SSB training arrangement with the arrangement of Grass Root exercises, namely: Warming up $11.57 \%$ versus $13.33 \%$, physical $23.15 \%$ versus $13.33 \%$, technique $28.70 \%$ versus $33.33 \%$, game $28.70 \%$ compared to $33.33 \%$, cooling $9.73 \%$ compared to $6.7 \%$. So the results of the data obtained from the three Football Schools in Kepahiang District, the existing training program is not in
\end{abstract}


accordance with the Grass Root training program recommended by Indra Sjafri and there is an exercise program that has not been implemented during training.

Keywords: Exercise Program, Grass Root, Football, Football School

\section{PENDAHULUAN}

Olahraga adalah aktivitas untuk melatih tubuh seseorang, tidak hanya secara jasmani tetapi juga secara rohani. Olahraga sangat bermanfaat bagi kesehatan tubuh. Dengan berolahraga metabolisme tubuh menjadi lancar sehingga distribusi dan penyerapan nutrisi dalam tubuh menjadi lebih efektif dan efisien. Salah olahraga yang populer dimasyarakat dari dulu hingga saat ini adalah sepak bola.

Sepak bola (bahasa Inggris: Football atau Soccer) adalah cabang olahraga yang menggunakan bola yang umumnya terbuat dari bahan kulit dan dimainkan oleh dua tim yang masing-masing beranggotakan 11 (sebelas) orang pemain inti dan beberapa pemain cadangan. Memasuki abad ke-21, olahraga ini telah dimainkan oleh lebih dari 250 juta orang di 200 negara, yang menjadikannya olahraga paling populer di dunia. Selain latihan kemampuan dasar, yang perlu diperhatikan juga adalah latihan fisik. Latihan dapat dilakukan sendiri atau terkoordinasi dalam sebuah klub atau pusat pelatihan. Kondisi fisik adalah satu kesatuan untuh dari komponen-komponen yang tidak dapat dipisah-pisahkan, baik peningkatannya maupun pemeliharaannya, artinya dalam usaha peningkatan kondisi fisik harus mengembangkan semua komponen tersebut. Untuk menigkatkan kondisi fisik dan kemampuan atau skill dalam permainan sepakbola diperlukan latihan-latihan yang sudah terprogram dengan baik dan pelaksanaan latihan harus sesuai dengan program yang sudah di tetapkan. Dengan demikian barulah bisa terbentuk atlet-atlet yang berprestasi. Program latihan sepak bola bagi anak dibagi menjadi tiga berdasarkan rentang usia, yaitu 6-12 tahun (Grass Root), usia 13-15 tahun (Youth Formative Phase), dan usia 16-19 tahun (Youth Final Phase) (Indra Sjafri 2017 : 5). Perlu diingat bahwa anak-anak kecil suka bermain, dan semakin banyak diberikan permainan, mereka akan semakin senang untuk belajar sepak bola (Robert Koger (2007 : 15)

\section{METODE}

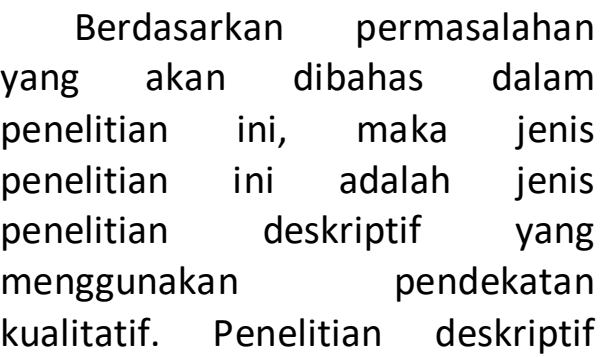


yang mengambarkan program latihan sekolah sepak bola di Kepahiang, melalui observasi atau pengamatan langsung, maksudnya penelitian ini adalah melihat langsung hasilnya dan tidak melihat dari proses awal, selanjutnya mencari penyebab masalah tersebut.

Sugiyono

(2012:

menyatakan bahwa metode survey digunakan untuk mendapatkan data dari tempat tertentu yang alamiah (bukan buatan), tetapi peneliti melakukan perlakuan dalam pengumpulan data, misalnya dengan mengedarkan kuesioner, tes, wawancara dan sebagainya. Teknik untuk memperoleh data di lapangan melalui observasi dan wawancara serta dengan dokumentasi.

1. Observasi : digunakan untuk mengetahui informasi tentang SSB Kabupaten Kepahiang.

2. Wawancara : berfungsi untuk mengetahui frofil dan program latihan di SSB Kabupaten Kepahiang

3. Dokumentasi : digunakan untuk mengumpulkan bukti bahwa SSB masih aktif

\section{HASIL DAN PEMBAHASAN}

Pelaksanaan

dalam penelitian ini dilakukan di Sekolah Sepak Bola Kabupaten Kepahiang. Penelitian ini bertujuan untuk mengetahui program latihan Sepak Bola Grass Root pada Sekolah Sepak Bola Kabupaten Kepahiang

yang $\begin{array}{rr}\text { Berdasarkan hasil data } \\ \text { diperoleh langsung }\end{array}$ dilapangan dengan mewawancarai pembina dan pelatih dan melihat langsung latihan pada sekolah sepak bola serta melihat administrasi organisasi. Diperolah hasil bahwa sekolah sepak bola Kabupaten Kepahiang program latihan untuk anak usia 6-12 tahun belum sesuai dengan karakter dan usia anak-anak. Seperti pada Sekolah Sepak Bola Kepahiang yang melakukan latihan fisik yang bisa dibilang cukup berat untuk anak-anak usia 6-12 tahun dan SSB Kepahiang implementasi program latihan di lapangan tidak sesuai dengan program latihan yang tertulis dalam kurikulum, sedangkan pada Sekolah Sepak Bola Bogor Jaya Fc dan Academy SMA Negeri 1 Kepahiang sudah mendekati program latihan untuk usia 6-12 tahun (grass root) yang disosialisasikan oleh Indra Sjafri yaitu anak-anak usia 6-12 tahun latihannya dengan memperbanyak bermain dengan bola. Berdasarkan hasil analisis tersebut perbandingan rata-rata persentasi susunan latihan SSB Kepahiang dengan susunan latihan Grass Root yaitu : Pemanasan 11,57\% berbanding $13,33 \%$, fisik $23,15 \%$ berbanding $13,33 \%$, teknik $28,70 \%$ berbanding $33,33 \%$, permainan $28,70 \%$ berbanding 33,33\%, pendinginan $9,73 \%$ berbanding $6,7 \%$.

Tabel Perbandingan susunan Latihan SSB Kepahiang dan Susunan latihan Grass Root

\begin{tabular}{l|c|c} 
Latihan & Rata-rata & Persentas \\
Persentas & e susunan \\
& e susunan & latihan \\
latihan & menurut \\
& SSB & Indra \\
& Kepahiang & Sjafri \\
\hline Pemanasan & $11,57 \%$ & $13,33 \%$
\end{tabular}




\begin{tabular}{l|l|l} 
Fisik & $23,15 \%$ & $13,33 \%$ \\
\hline Teknik & $28,70 \%$ & $33,33 \%$ \\
\hline Permainan & $28,70 \%$ & $33,33 \%$ \\
\hline Pendingina & $9,73 \%$ & $6,7 \%$ \\
\hline Jumlah & $100 \%$ & $100 \%$
\end{tabular}

Gambar persentase susunan latihan SSB Kabupaten Kepahiang.

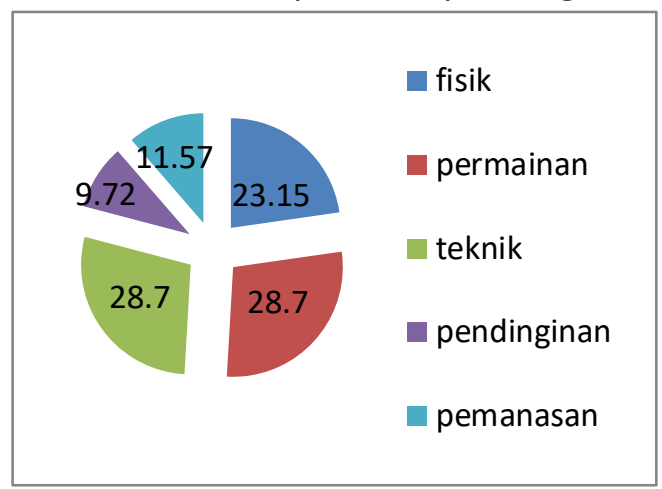

Gambar persentase susunan latihan Grass Root.

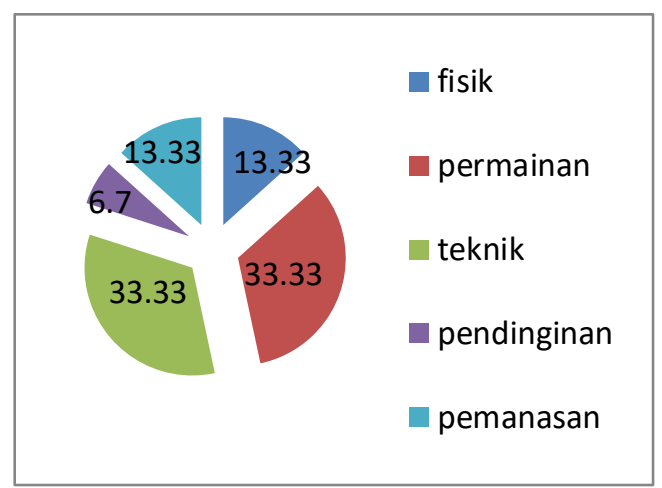

Berdasarkan hasil analisis tersebut berarti program latihan sepak bola pada pemain usia 6-12 tahun di SSB Kabupaten Kepahiang dalam permainan sepak bola sudah cukup baik tapi belum sesuai dengan program latihan untuk anak usia 6-12 tahun atau grass root.

\section{PENUTUP \\ Simpulan}

Berdasarkan pada hasil penelitian yang telah peroleh dari program latihan dan implementasinya maka dapat diambil kesimpulan bahwa program latihan sepakbola pada pemain usia 6-12 tahun di Kabupaten Kepahiang masih belum teratur dan tidak diterapkan pada saat latihan dan masih belum sesuai dengan program latihan usia 6-12 tahun (grass root). Dengan hasil perbandingan persentasi sebagai berikut.

Dikarenakan program latihan yang kurang teratur dan tidak diterapkan pada latihan dan belum sesuai dengan usia 6-12 tahun (grass root) yang mempengaruhi kemampuan yang muncul sangat awal dan muncul kejenuhan latihan pada pemain usia 6-12 tahun tersebut. Dengan tidak teraturnya program latihan dan belum sesuai dengan usia serta Sekolah Sepak Bola yang masih dalam kategori usia muda. Karena itu prestasi sepak bola Kabupaten Kepahiang saat ini masih kalah dengan prestasi sepak bola dari daerah lain seperti Kabupaten Rejang Lebong, Kabupaten Benteng dan Kota Bengkulu dan daerah yang lain juga.

\section{Saran-saran}

Berdasarkan simpulan hasil penelitian di atas maka ada beberapa hal yang perlu disarankan.

1. Sesuai dengan hasil penelitian bahwa program latihan sepak bola pada sekolah sepak bola 
Kabupaten Kepahiang belum teratur tidak diterapkan pada latihan dan belum sesuai dengan programlatihan usia 6 12 tahun (grass root), maka dari itu Sekolah Sepak Kabupaten Kepahiang harus meningkatkan program latihan agar lebih teratur dan program latihan yang dimiliki harus diterapkan pada saat latihan.

2. Dengan belum teraturnya program latihan sepak bola dan belum diterapkan pada latihan dan belum sesuai dengan program latihan untuk anakanak usia 6-12 tahun (grass root), hal ini dapat dijadikan bahan kajian bagi para pelatih untuk meningkatkan ilmu pengetahuan untuk kemajuan SSB Kabupaten Kepahiang.

3. Penelitian ini juga bertujuan sebagai refensi pelatih dimana pelatih bisa mengetahui dimana letak kekurangan timnya sehingga bisa memperbaiki tim sepakbola tersebut agar dapat menciptakan atlet yang berbakat dan mendapatkan prestasi yang baik.

4. Hasil penelitian ini juga digunakan sebagai bahan evaluasi bagi pelatih untuk mengetahui apakah sudah benar program latihan yang diterakanya sesuai dengan usia pemain.

\section{DAFTAR PUSTAKA}

Arsil, 2010. Evaluasi Pendidikan Jasmanin dan Olahraga. Padang: Wineka Media.

Gifford, Clive. 2007. Ketrampilan Sepak Bola. Klaten : PT Citra Aji Parama.
Hanaf, A.A. 2012, Subjek dan Objek Penelitian. Lengkap di http://afdholhanaf.blogspot.co $\mathrm{m} / 2012 / 03 /$ subjek-dan-objekpenelitian.html. (akses 14 Februari 2019 pukul 14.00 wib).

IFAB. 2014. Laws Off The Game Football. Swittzerland : Federation Internatoinale de Football Association.

Juniansyah. K.R 2013. Analisis Kemampuan Fisik dan Ketrampilan Teknik Dasar Atlet Sepakbola Ps.Bengkulu. (Skripsi). Bengkulu (ID) : Universitas Bengkulu.

Koger, Robert. 2007Latihan Dasar Andal Sepak Bola Remaja. Klaten : PT Saka Mitra Kompetensi

Kurikulum Sekolah Sepak Bola Kepahiang

Kurniawan, F. (2012). Buku Pintar Pengetahuan Olahraga. Jakarta Timur: Laskar Laksara.

Leo, Arwin, dan Syafrial. 2017. "Profil Kondisi Fisik Pemain Sepak Bola SMA Negeri 1 Kaur" Jurnal Kinestetik, Vol. 1 (1).

Mielke, Danny. 2007. Dasar-dasar Sepak Bola. Bandung : Pakar Raya

Nurhasan. (2001). Tes dan Pengukuran Pendidikan Olahraga. Bandung:

Universitas Pendidikan Indonesia.

Pujianto, Dian. Insanistyo, Bayu. 2017. Dasar-dasar Penelitian 
Pendidikan Jasmani. Bengkulu : FKIP Universitas Bengkulu.

Utama, M.W 2017. Analisis Kemampuan teknik dasar Bermain Sepak Bola Pada Pemain Usia 16 Tahun Di SSB Kabupaten Rejang Lebong (skripsi). Bengkulu (ID) : Universitas Bengkulu.

Siregar, F.M. 2018. Analisis SMA Negeri Berprestasii di Bidang Ekstrakulikuler Futsal Kota Bengkulu. Jurnal KINESTETIK, Vol 2 (1) hal. (1).

Sjafri, Indra. 2017. Panduan Keplatihan Sepak Bola Anak. Jakarta: Penerbit Esensi, Erlangga Group.

Sugiyono. 2012. Metode Penelitian Kuantitatif Kualitatif dan $R \& D$. Bandung : $\mathrm{CV}$ ALFABETA.

Sukatamsi. 2005. Permaianan Besar 1 Sepak Bola. Jakarta : Universitas Bengkulu 